\title{
Eye acupuncture in Malaysia: the need for guidelines, regulation and enforcement
}

\author{
Mohamad Aziz Salowi $\mathbf{i}^{1,2}$
}

${ }^{1}$ Department of Ophthalmology, Selayang Hospital, Selangor, Ministry of Health, Malaysia; ${ }^{2}$ Department of Ophthalmology, Faculty of Medicine, Universiti Sultan Zainal Abidin, Kuala Terengganu, Malaysia

Acupuncture originates from the practice of the ancient Chinese more than 2000 years ago. ${ }^{1}$ It was initially performed using sharp stones, bone, or bamboo, before the discovery of metals. In modern days, the needles are made of stainless steel and can vary from 5 to $23 \mathrm{~cm}$ in length. ${ }^{1}$ Eye acupuncture involves the application of these needles to multiple acupoints around the orbital area. ${ }^{2}$ In eye care, acupuncture has been reported to be used in treating myopia, glaucoma, retinitis pigmentosa, and cranial nerve paralysis. ${ }^{3-6}$ It is increasingly being used for the treatment of dry eye. ${ }^{7}$ Eye acupuncture has also been reported to be used as the primary treatment or adjuvant therapy to treat other ailments not related to the eye. ${ }^{8,9}$ The usage of needles in eye-acupuncture exposes individuals to ocular injury due to the close proximity of the eyeball or critical orbital structures to the acupoints. Poor sterilization practices and the usage of recycled instruments may lead to infection or transmission of sexually transmitted diseases. ${ }^{10}$ Therefore, anatomical knowledge of the orbit and eyeball as well as adherence to standard ethical practices are mandatory for all acupuncturists. Reported adverse effects are not uncommon. They range from superficial conjunctival haemorrhage to penetrating ocular injury, resulting in traumatic cataract, subretinal track, vitreous haemorrhage, proliferative vitreoretinopathy, or endophthalmitis. ${ }^{6,11-15}$ In this current issue, Ainal et al. highlighted six cases of ocular injuries related to acupuncture in their brief report. ${ }^{15}$

In the local setting, Traditional and Complementary Medicine (T/CM) has been integrated into the Malaysian Healthcare System. Although other types of acupuncture services are available and listed for general information in the Annual Report and the Consumer Guideline, eye acupuncture services are not available yet in public hospitals. ${ }^{16,17}$ The National Guidelines for these non-eye acupuncture services are available for both healthcare providers and consumers. ${ }^{17,18}$ Essential information, such as the location of the acupuncturist, contact number, type of acupuncture services offered, and complaint or feedback line, is also available 
to the public. ${ }^{17}$ Like other T/CM services in the country, they are governed by the National Policies and Law on Traditional and Complementary Medicine.

The National Policy was developed by the Traditional and Complementary Medicine Division of the Malaysian Ministry of Health (MOH) in $2002 .{ }^{19}$ It states that the T/CM system should be an essential component of the Healthcare System, coexisting with modern medicine and contributing towards enhancing the health and quality of life of all Malaysians. The Act on Traditional and Complementary Medicine (Act 775: 2016) came to full enforcement on August 1, 2016. It allows the Traditional and Complementary Medicine Council to regulate the T/CM services in Malaysia. It also requires T/CM practitioners to register in the T/CM Practitioner Bodies, the National Bodies registered with the Registrar of Societies and appointed by the $\mathrm{MOH}$. This appointment allows this body to self-regulate its practitioners through codes of ethics and practice regulated by the $\mathrm{T} / \mathrm{CM}-\mathrm{MOH}$ standing committee and endorsed by the T/CM council. ${ }^{20}$

The case series included in this issue of Malaysian Journal of Opthalmology highlights the possible hidden magnitude of the problem in the country. Within seven months (from April 2019 to October 2019), six cases of ocular injury following eye acupuncture treatment presented to different ophthalmologists in the country. The number could probably be higher if the writer extended the duration of the case series reporting or if the related enforcement body performed an active case tracing at the same time. The multiple incidences of acupuncture-related eye injury occurring within a short period suggests a possible error in the notification system (either within the healthcare system or within the community), if the notification system existed at all. It also shows a lack of coordination and possible lack of awareness among acupuncturists, ophthalmologists, and the T/CM Practitioner Body regarding the risk of unmonitored eye acupuncture practice to the public.

When properly regulated and monitored, eye acupuncture may contribute favourably to the community's eye healthcare. T/CM Practitioner Bodies and Councils, as organizations mentioned in the Act, need to monitor and evaluate the process of registering acupuncturists, develop standards and ethics frameworks, and regulate the practice of eye acupuncture. The regulation shall include stringent certification and penalties for breach of professional conduct and rules. The $\mathrm{T} / \mathrm{CM} \mathrm{MOH}$ Division shall develop a policy and guidelines on acupuncture involving the eye as well as provide a platform to host notification and encourage communication among the practitioners. The Prevention of Blindness Committee in the $\mathrm{MOH}$ shall work together with the $\mathrm{T} / \mathrm{CM} \mathrm{MOH}$ Division in planning to prevent further occurrence of acupuncture-related ocular injuries in the community. Most importantly, the public must be informed through the media and social media platforms regarding the standard conducts in eye acupuncture and the potential risks of the procedure. 


\section{References}

1. Koh EK. Acupuncture. Br J Gen Pract. 1973;23:265-72.

2. Shao Y, Wang P, Wang Q, et al. Eye-acupuncture with rehabilitation therapy for stroke. Medicine (Baltimore). 2020;99(18):e20096.

3. Dabov S, Goutoranov G, Ivanova R, Petkova N. Clinical application of acupuncture in ophthalmology. Acupunct Electrother Res. 1985;10(1-2):79-93..

4. Law SK, Lowe S, Law SM, et al. Prospective Evaluation of Acupuncture as Treatment for Glaucoma. Am J Ophthalmol. 2015;160(2):256-65.

5. Ji XJ, Zhou LY, Si CQ, et al. [Efficacy observation on electroacupuncture in the treatment of oculomotor impairment caused by ophthalmic nerve injury]. Zhongguo Zhen Jiu. 2013;33(11):975-979.

6. You TT, Youn DW, Maggiano J, et al. Unusual ocular injury by an acupuncture needle. Retin Cases Brief Rep. 2014;8(2):116-119.

7. Dhaliwal DK, Zhou S, Samudre SS, et al. Acupuncture and dry eye: current perspectives. A double-blinded randomized controlled trial and review of the literature. Clin Ophthalmol. 2019;13:731-740.

8. Lin Q, Hu YL, Han CW, Li Y. [Eye acupuncture for treatment of renal and ureteral colic]. Zhongguo Zhen Jiu. 2007;27(9):663-664.

9. Shaoa Y, Wang M, Liu B, et al. Eye-acupuncture as adjuvant therapy for stroke: A bibliometric analysis of clinical studies. Journal of Traditional Chinese Medical Sciences 2019;6(3):263-69.

10. Woo PCY, Lin AWC, Lau SKP, et al. Acupuncture transmitted infections. BMJ. 2010;340:c1268.

11. Denstedt J, Schulz DC, Diaconita V, et al. Acupuncture resulting in eye penetration and proliferative vitreoretinopathy - Surgical and medical management with intraocular methotrexate. Am J Ophthalmol Case Rep. 2020;18:100605.

12. Fielden M, Hall R, Kherani F, et al. Ocular perforation by an acupuncture needle. Can J Ophthalmol. 2011;46(1):94-95.

13. Kao TE, Kuo YW, Wu KY. Acupuncture-related penetrating eye injury. Kaohsiung J Med Sci. 2017;33(9):473-474.

14. Shuang $\mathrm{H}$, Yichun $\mathrm{K}$. A case of perforating injury of eyeball and traumatic cataract caused by acupuncture. Indian J Ophthalmol. 2016;64(4):326-327.

15. Naffi AA, Ling KP, Ratanam M, Kong VYP, Fong CSK, Bastion MLC. A series of acupuncture-related ocular injuries in Malaysia. Malaysian Journal of Ophthalmology. 2021;3(1):30-38.

16. Ministry of Health Malaysia. Annual Report. Traditional and Complementary Division. Kuala Lumpur; Ministry of Health: 2019.

17. Ministry of Health Malaysia. Consumer Guideline: FOR PROPER USE OF TRADITIONAL AND COMPLEMENTARY MEDICINE SERVICES IN MALAYSIA: Traditional and Complementary Medicine Division Ministry of Health Malaysia, 2019.

18. Ministry of Health Malaysia. Practice Guideline on Acupuncture. Kuala Lumpur: Traditional and Complementary Medicine Division; 2017.

19. Ministry of Health Malaysia. National Policy on Traditional and Complementary Medicine. Kuala Lumpur: Traditional and Complementary Medicine Division; 2002.

20. Malaysia Government. Laws of Malaysia - Act 775: Traditional and Complementary Medicine Act 2016: Percetakan Nasional Malaysia Berhad 2016. 